\title{
ANALISIS STRATEGI KOMUNIKASI KRISIS HUMASDA PT. KERETA API INDONESIA (PERSERO) DAERAH OPERASIONAL 2 BANDUNG (Studi Deskriptif Dalam Kasus Penertiban Lahan Stasiun Barat)"
}

\author{
${ }^{1}$ Adzkia Arif, ${ }^{2}$ Dr. Ayub Ilfandy Imran, B.Sc., M.Sc \\ Prodi S1 Ilmu Komunikasi, Fakultas Komunikasi dan Bisnis, Universitas Telkom \\ Adzkiaarif95@gmail.com¹, a_ilfandy@yahoo.com²
}

\begin{abstract}
The research is titled "Analyses of Crisis Communication Strategy of Humasda PT. Kereta Api Indonesia (PERSERO) Operation Area 2 Bandung (Descriptive Study in Case of Evacuation Land in West Station)", as for the problem are the concept of crisis processing, the crisis communication strategy, the effort in cope with crisis, PR role when the crisis held by Humasda PT. Kereta Api Indonesia (Persero) Operational Area (Daop) 2 Bandung in solve the crisis that caused by evacuation land in west station. This research used case study qualitative research method of case study along with descriptive exposure. The data obtained through observation, interview, and documents. The main informant in this research is Staff of Humasda Expert PT. KAI Daop 2 Bandung, with the support informant are college student activist, and Kebon Jeruk citizen. Result of this research is crisis communication strategy held by Humasda PT. Kereta Api Indonesia (Persero) Operational Area 2 Bandung already implemented, start from the existence of strategy in cope with crisis, existence of crisis center, and strategy of good media communication. However, the weakness of crisis communication strategy implementation by Humasda PT. Kereta Api Indonesia (Persero) Operational Area 2 Bandung is not doing any direct communication event to the society who give a gap for a developing more crisis.
\end{abstract}

Keywords: Crisis, Crisis Communication, Public Relations

\section{PENDAHULUAN}

T. Kereta Api Indonesia (Persero)
merupakan salah satu perusahaan BUMN yang bergerak dalam bidang transportasi darat yang memberikan pelayanan dalam mengangkut penumpang dan barang. PT. Kereta Api Indonsia (Persero) yang untuk selanjutnya disebut dengan PT. KAI. Sebagai salah satu penyedia sarana transportasi darat terbesar di Indonesia, PT. KAI tentunya berupaya memberikan kenyamanan bagi para pengguna jasanya. Stasiun merupakan salah satu fasilitas utama yang dimiliki oleh PT. KAI. Stasiun menjadi pusat keberangkatan dan kedatangan bagi orang yang menggunakan jasa transportasi kereta api. Sebagai salah satu saran utama, sudah semestinya PT. KAI mengupayakan kenyaman dan keamanan yang bisa didapatkan oleh konsumen mereka di stasiun.

PT. KAI Daerah Operasional (Daop) 2 Bandung merupakan salah satu dari kantor cabang PT. KAI yang berlokasi di pintu stasiun barat, kota Bandung. Sebagai bentuk pelayanan dan pemenuhan kebutuhan konsumen dalam hal kenyamanan saat di stasiun, PT. KAI Daop 2 Bandung berencana melakukan penataan lahan parkir, perbaikan drainase, serta pemasangan gate-in dan gate-out. Rencana penataan lahan parkir ini ternyata menjadi awal bagi krisis yang menimpa PT. Kereta 
Api Indonesia, Daerah Operasional 2 Bandung. Penolakan dilakukan oleh masyarakat sebagai akibat dari rencana penggusuran yang dilakukan oleh PT. KAI untuk mewujudkan lahan parkir tersebut, krisis ini berbuntut Panjang hingga ke ranah hokum yanng sampai detik ini masih belum ditemukan titik temunya. Terkait dengan krisis yang terjadi, peran public relations PT. KAI Daop 2 Bandung menjadi hal yang penting sebagai salah satu sarana perusahaan untuk menyelesaikan permasalahan yang tengah terjadi. Komunikasi yang dibangun oleh public relations perusahaan dengan masyarakat luas, baik secara langsung ataupun lewat pemberitaan media akan sangat bermanfaat dalam membentuk persepsi masyarakat dan menjaga citra baik dari perusahaan.

Oleh karena itu, dengan adanya kasus ini, maka penulis ingin melakukan penelitian untuk meninjau lebih lanjut strategi PR PT. KAI Daop 2 Bandung dalam menangani krisis yang berkaitan dengan strategi komunikasi langsung dan komunikasi media yang diterapkan dengan judul penelitian adalah "ANALISIS STRATEGI KOMUNIKASI KRISIS HUMASDA PT. KERETA API INDONESIA (PERSERO) DAERAH OPERASIONAL 2 BANDUNG (Studi Deskriptif Dalam Kasus Penertiban Lahan Stasiun Barat)

\section{KAJIAN PUSTAKA}

\section{Krisis}

Firsan Nova (2014:3) menjelaskan bahwa krisis adalah setiap peristiwa (event) yang kehadirannya dapat membahayakan atau mengancam citra, reputasi, ataupun stabilitas keuangan suatu organisasi. Lebih lanjut, Robert P. Powell dalam bukunya Crisis-A Leadership Opportunity yang tertuang dalam karangan Firsan Nova, Robert P. Powell (dalam Nova, 2014:3) menyatakan bahwa krisis adalah kejadian yang tidak diharapkan, berdampak dramatis, kadang belum pernah terjadi sebelumnya yang mendorong organisasi kepada suatu kekacauan (chaos), dan dapat menghancurkan organisasi tersebut tanpa ada tindakan nyata. Krisis tidak memiliki batas (no boundaries) dan dapat terjadi kapan saja dan dimana saja terhadap setiap organisasi.

\section{Manajemen Krisis}

Coombs (dalam Kriyantono, 2015:219) mendefinisikan manajemen krisis sebagai " a set of factors designed to combat crises and to lessen the actual damages inflicted, seeks the prevent or lessen the negatives outcomes of a crisis and thereby protect the organization, stakeholders, and/or industry from damages." Jika diterjemahkan ke dalam bahasa Indonesia, maka dapat diartikan sebagai seperangkat faktor yang dirancang untuk memerangi krisis dan untuk mengurangi kerusakan yang dapat ditimbulkan, mencari pencegahan atau mengurangi dampak negatif dari sebuah krisis dan dengan demikian melindungi organisasi, pemangku kepentingan, dan/atau industri dari kerusakan. Sedangkan menurut Gary Kreeps (1990) dalam Kriyantono (2015:221) manajemen krisis merupakan sebuah proses yang menggunakan aktivitas public relations untuk mengatasi akibat negatif, misalnya 
kerusakan-kerusakan yang dialami organisasi.

\section{Tahapan Krisis}

Menurut Firsan Nova (2014:13) terdapat lima tahapan dalam siklus hidup krisis yang harus dikenali dan dipahami. Lima tahapan siklus hidup krisis tersebut adalah .

a. Tahap pre-crisis (sebelum krisis)

Pre-crisis adalah kondisi sebelum sebuah krisis muncul. Benih krisis sudah ada sehingga jika muncul suatu kesalahan yang kecil saja, krisis dapat terjadi.

b. Tahap warning (peringatan)

Tahap ini dianggap sebagai salah satu tahap yang paling penting dalam daur hidup krisis. Tahap warning merupakan kondisi dimana masalah pertama kali dikenali, dan dalam hal ini perusahaan memiliki pilihan untuk segera mengatasi krisis pada tahap ini atau dibiarkan hingga krisis membawa resiko yang lebih serius.

c. Tahap acute crisis (akut)

Pada tahap ini krisis mulai terbentuk dan media juga publik mulai mengetahui adanya masalah.

d. Tahap clean-up (pembersihan)

Tahap clean-up merupakan saat dimana perusahaan harus memulai bangkit dari serangan krisis, memulai memperbaiki kinerja dan citra perusahaan di hadapan para stakeholders.

e. Tahap post-crisis (sesudah krisis)

Inilah tahap yang telah disebutkan sebelumnya, yakni perusahaan seharusnya bereaksi saat suatu krisis muncul ke tahap warning. Jika sejak awal tidak dihentikan, krisis akan terjadi. Jika perusahaan memenangkan kembali kepercayaan publik dan dapat beroperasi kembali dengan normal, maka secara formal dapat dikatakan krisis telah berakhir.

\section{Komunikasi Krisis}

Fearn-Banks menyebut komunikasi krisis sebagai "the dialog between the organization and its public prior to, during, and after the negative occurrence. The dialog details strategies and tactics are designed to minimize damage to the image of the organization". (Kriyantono, 2015:239) Jika diartikan kedalam bahasa, maka pengertiannya adalah komunikasi krisis merupakan dialog atau komunikasi antara organisasi dengan publiknya sebelum, selama, dan setelah terjadinya krisis. Merancang strategi dan taktik dialog atau komunikasi untuk meminimalkan dampak negatif yang disebabkan oleh krisis terhadap citra perusahaan.

Definisi lainnya tentang komunikasi krisis juga dikemukakan oleh Coombs (dalam Kriyantono, 2015:244), komunikasi krisis adalah "collection, processing, and dissemination of information required to address a crisis situation." Karena itu, disimpulkan jika "Communication is the essence of crisis management". Dalam bahasa, definisi komunikasi krisis yang dikemukakan oleh Coombs adalah pengumpulan, pengolahan, dan penyebarluasan informasi yang dibutuhkan untuk mengatasi situasi krisis. Menurut Coombs komunikasi adalah inti dari manajemen krisis. 


\section{Public Relations}

Scott Cutlip, Allen Center, dan Glen Broom (dalam Kriyantono, 2015:2) menyebutkan bahwa public relations sebagai fungsi manajemen yang membangun dan mempertahankan hubungan baik dan bermanfaat dengan publiknya yang memengaruhi kesuksesan atau kegagalan organisasi. Definisi lainnya tentang public relations juga dikemukakan oleh Frank Jefkins (dalam Suryanto dan Gassing, 2016:9), bahwa PR adalah sesuatu yang merangkum keseluruhan komunikasi yang terencana, baik ke dalam maupun ke luar, antara suatu organisasi dengan khalayaknya dalam rangka mencapai tujuan-tujuan yang spesifik berlandaskan pada saling pengertian.

\section{Strategi PR dalam Menghadapi Krisis}

Cutlip and Center (dalam Nova, 2014:25) mengemukakan pemikiran tentang proses kerja PR, diantaranya adalah:

\section{a. Fact Finding}

Mendefinisikan permasalahan yang dilakukan melalui penelitian dengan menganalisis situasi berupa pemahaman, opini, sikap, dan perilaku public terhadap lembaga.

\section{b. Planning}

Berdasarkan pada rumusan masalah, dibuat strategi perencanaan dan pengambilan keputusan untuk membuat program kerja berdasarkan kebijakan lembaga yang juga disesuaikan dengan kepentingan publik.

c. Communicating

Dalam tahap ini PR harus mengomunikasikan pelaksanaan program sehingga mampu memngaruhi sikap publiknya yang mendorong mereka untuk mendukung pelaksanaan program tersebut.

d. Evaluating

Tahap ini melakukan penelitian terhadap hasil-hasil pelaksanaan program dari perencanaan, pelaksanaan program, proses komunikasi, sampai keberhasilan atau kegagalan yang terjadi dari program tersebut.

\section{Media Relations}

Lesly (dalam Iriantara, 2011:29) menjelaskan media relations sebagai hubungan dengan media komunikasi untuk melakukan publisitas atau merespons kepentingan media terhadap organisasi. Berbeda dengan Lesly, Franks Jefkins (dalam Darmastuti, 2012:42) mendefinisikan media relations sebagai usaha untuk mencari publikasi atau penyiaran yang maksimum atas suatu pesan atau informasi humas dalam rangka menciptakan pengetahuan dan pemahaman bagi khalayak dari organisasi perusahaan yang bersangkutan.

Iriantara (dalam Imran, 2017:118) menjelaskan bahwa media relations merupakan salah satu kegiatan humas eksternal yang membina dan mengembangkan hubungan baik dengan media massa sebagai sarana komunikasi antara organisasi dengan publik untuk mencapai tujuan organisasi. Ada kriteria agar kegiatan media relations berjalan dengan baik, menurut Imran (2017:118), kriteria tersebut adalah:

a. Komitmen, yang berkenaan dengan kesungguhan dari setiap pihak yang terlibat dalam program untuk memberikan hasil terbaik. 
b. Kejelasan, yang berkenaan dengan pesan yang hendak disampaikan itu jelas dan sederhana.

c. Konsistensi, yang berkaitan dengan konsistensi dalam maksud dan tujuan. Serta konsistensi dalam citra yang hendak dikembangkan.

d. Kreativitas, yang berkaitan dengan caracara yang kita kembangkan untuk menjalin hubungan dengan media, penyusunan pesan, kegiatan yang dijalankan dalam program tersebut dan seterusnya.

\section{METODE PENELITIAN}

Metode penelitian yang digunakan dalam penelitian ini adalah metode kualitatif studi kasus dengan pemaparan secara deskriptif.. Pada penelitian ini penulis menggunakan Teknik purposive sampling yaitu teknik pengambilan sample sumber data dengan pertimbangan tertentu.

\section{PEMBAHASAN}

\section{Tahapan Krisis}

\section{a. Tahap Pre-Crisis}

Pre-crisis adalah kondisi sebelum sebuah krisis muncul. Benih krisis sudah ada sehingga jika muncul suatu kesalahan yang kecil saja, krisis dapat terjadi. Banyak perusahaan yang tidak menaruh perhatian pada benih krisis yang mulai muncul ini, benih krisis yang dibiarkan akan memberi dampak yang buruk pada perusahaan dimasa depan, apalagi jika perusahaan tidak memiliki strategi manajemen krisis yang baik (dalam Nova, 2014:13).

Berdasarkan pengertian di atas dan dari hasil wawancara yang telah dilakukan, peneliti menyimpulkan bahwa sebelum krisis terjadi, Humasda PT. KAI Daop 2 Bandung telah memiliki strategi khusus untuk menangani krisis, dan telah memiliki crisis center untuk mengantisipasi krisis.

\section{b. Tahap Warning}

Tahap ini dianggap sebagai salah satu tahap yang paling penting dalam daur hidup krisis. Tahap warning merupakan kondisi dimana masalah pertama kali dikenali, dan dalam hal ini perusahaan memiliki pilihan untuk segera mengatasi krisis pada tahap ini atau dibiarkan hingga krisis membawa resiko yang lebih serius. Krisis dapat dengan mudah muncul pada tahap ini karena ketakutan menghadapi "badai" atau "masalah" dan menganggapnya tidak ada. Reaksi yang umum terjadi pada tahap ini adalah kaget atau menyangkal dan pura-pura merasa aman (dalam Nova, 2014:13).

Pada tahap warning dimana krisis menjadi sebuah peringatan bagi perusahaan, pertama kali yang harus dilakukan adalah berkoordinasi secara internal perusahaan agar pada tahap ini tidak terjadi kepanikan dan semua karyawan dapat bekerja dengan norman dan profesional. Kemudian terkait dengan masalah keamanan, yang harus dilakukan oleh Humasda Daop 2 adalah berkomunikasi kepada opinion leader terkait aksi yang akn dilaksanakan, mendiskusikan apakah ada solusi yang baik sebelum turunnya aksi, dan pun jika akan ada aksi, diharapkan masyarakat dapat menjaga kemanan dan ketertiban. Selanjutnya untuk menanggapi pemberitaan yang mungkin akan muncul di media, Humasda Daop 2 sebaiknya memberikan informasi kepada media tanpa 
ada yang ditutupi. Sehingga masyarakat nantinya dapat menilai siapa yang benar dan salah dalam kasus yang terjadi.

\section{c. Tahap Acute Crisis}

Pada tahap ini krisis mulai terbentuk dan media juga publik mulai mengetahui adanya masalah. Pada tahap ini, seharusnya perusahaan memberikan aksi yang cepat dan tepat karena krisis sudah mulai mengancam perusahaan. Saat inilah kesiapan perusahaan dilihat dalam menyambut krisis, baik dari segi kesiapan sumber daya manusia maupun strategi manajemen krisis nya (dalam Nova, 2014:13).

Jika dilihat dengan sudut pandang yang lebih luas, tahapan ini bukanlah hal yang harus dikhawatirkan oleh perusahaan dalam hal keberlangsungan hidup. Karena operasional perusahaan sama sekali tidak terganggung dalam hal ini, dapat tetap beraktivitas sebagaimana biasanya. Namun sebagaiman yang telah dijelaskan diatas, yang lebih dikhawatirkan adalah dampak terhadap citra perusahaan, maka dari itu Humasda Daop 2 harus mampu menghadapi media dengan startegi media yang baik dan mampu memberikan informasi yang dibutuhkan secara terbuka agar masyarakat menjadi tahu mengenai konflik yang sedang terjadi.

\section{d. Tahap Clean-Up}

Tahap clean-up merupakan saat dimana perusahaan harus memulai bangkit dari serangan krisis, memulai memperbaiki kinerja dan citra perusahaan di hadapan para stakeholders. Pada tahapan ini perusahaan dapat mengambil pelajaran dari krisis yang terjadi dan dapat menyiapkan strategi untuk menghadapi kemungkinan krisis di masa mendatang (dalam Nova, 2014:13).

Setelah terjadinya krisis yang dihadapi oleh Humasda PT. KAI Daop 2 Bandung, maka humasda Daop 2 melakukan tahap pembersihan terhadap citra PT. KAI Daop 2 secara internal maupun eksternal. Secara internal hal yang dilakukan adalah membuat release kepada seluruh cabang PT. KAI di Indonesia dan juga kantor pusat, bahwanya krisis telah selesai dan dapat ditangani dengan baik oleh Humasda Daop 2 Bandung. Secara eksternal yang dapat dilakukan adalah membuat release dan menggelar konferensi pers untuk menjelaskan situasi terkini kepada masyarakat terkait krisis yang telah terjadi.

Kemudian, belajar dari krisis yang telah terjadi, PT. KAI dapat memberikan pembelajaran lebih kepada seluruh karyawan mengenai hal yang harus dilakukan ketika krisis kembali terjadi. Kemudian dapat juga dilakukan evaluasi terhadap strategi dalam menangani krisis dan standar operasional PT. KAI dalam melaksanakan kegiatan penertiban, terutama dalam bidang komunikasi secara langsung kepada masyarakat. Tujuannya adalah agar pada saat krisis kembali terjadi dengan permasalahan yang sama, Humasda Daop 2 sudah siap dengan strategi dan penanganan yang lebih baik dari sebelumnya.

\section{e. Tahap Post-crisis}

Inilah tahap yang telah disebutkan sebelumnya, yakni perusahaan seharusnya bereaksi saat suatu krisis muncul ke tahap warning. Jika sejak awal tidak dihentikan, krisis akan terjadi. Jika perusahaan 
memenangkan kembali kepercayaan publik dan dapat beroperasi kembali dengan normal, maka secara formal dapat dikatakan krisis telah berakhir (dalam Nova, 2014:13). Pada tahap terakhir yaitu tahap setelah krisis yang terjadi pada PT. KAI Daop 2 Bandung merupakan pemberitaan di media yang tidak lagi terpusat pada aktifitas penggusuran yang dilakukan oleh Daop 2, namun telah beralih kepada pemberitaan lain sebagai aktifitas lanjutan pasca penggusruan seperti ditemukannya hal unik di lokasi penggusuran dan rencana relokasi oleh pemerintah daerah kepada masyarakat yang tergusur.

Kemudian dalam tahap ini juga dapat menjadi pelajaran bagi PT. KAI untuk mampu mengamankan asset mereka agar tidak ditempati oleh masyarakat, atau jika sudah ditempati PT. KAI dalam memulai sosialisasi lebih awal dengan informasi dan bukti kepemilikan yang jelas, dan tentunya mampu memberikan solusi yang dapat diterima oleh kedua belah pihak dengan bantuan pemerintah atau pihak yang berwenang.

\section{Upaya Mengelola Krisis}

\section{a. Fact Finding}

Mendefinisikan permasalahan yang dilakukan melalui penelitian dengan menganalisis situasi berupa pemahaman, opini, sikap, dan perilaku publik terhadap lembaga. Seorang praktisi PR harus mampu menemukan akar dari permasalahan yang dihadapi untuk kemudian dijadikan sebagai landasan untuk menyusun strategi pencegahan atau pemecahan masalah yang tepat guna (dalam Nova, 2014: 25). Pada tahapan fact- finding, Humasda Daop 2 sudah mengadakan proses sosialisasi dan mediasi dengan masyarakat, dalam tahap factfinding ini masyarakat menginginkan adanya pengukuran kembali lahan yang ingin digusur oleh PT. KAI karena masyarakat menilai bahwa kelurahan Kebon Jeruk Bandung tidak termasuk dalam wilayah penggusuran. Hal ini kemudian dikabulkan oleh Humasda sebagai langkah untuk mengurangi konflik.

\section{b. Planning}

Berdasarkan pada rumusan masalah, dibuat strategi perencanaan dan pengambilan keputusan untuk membuat program kerja berdasarkan kebijakan lembaga yang juga disesuaikan dengan kepentingan publik. Strategi ini sebaiknya mendapat dukungan penuh dari petinggi perusahaan, agar nantinya seluruh kebutuhan yang berkaitan dengan strategi yang diterapkan dapat tepenuhi (dalam Nova, 2014:25). Tahap planning sudah dilakukan dengan benar oleh Humasda Daop 2 Bandung. Pihak Humasda menyiapkan data dan berkomunikasi dengan unit lain dibawah perintah Executive Vice President. Hal ini berarti setiap langkah yang diambil oleh Humasda Daop 2 Bandung mendapat persetujuan dari semua elemen PT. KAI Daop 2 Bandung, mulai dari lapisan bawah hingga lapisan paling teratas.

\section{c. Communicating}

Dalam tahap ini PR harus mengomunikasikan pelaksanaan program sehingga mampu memengaruhi sikap publiknya yang mendorong mereka untuk mendukung pelaksanaan program tersebut. Dalam mengomunikasikan sesuatu, 
seorang PR hendaknya mengesampingkan asumsi pribadi, seorang praktisi PR hendaknya mengomunikasikan sesuatu berdasarkan fakta dan data yang telah terkumpul dari dua langkah sebelumnya (dalam Nova, 2014:25). Ada dua jenis komunikasi yang dapat dilakukan pada saat terjadinya krisis, yaitu komunikasi langsung dan komunikasi media. Dalam hal ini, dari segi komunikasi langsung sulit untuk dilakukan karena kedua belah pihak sama-sama merasa benar. Untuk itu adanya pihak ketiga yang benar-benar netral sangat dibutuhkan untuk kemudian kedua belah pihak sama-sama menghormati dan menerima keputusan yang didapatkan. Untuk komunikasi kepada media, pihak Humasda Daop 2 sebaiknya mampu untuk membeberkan data dan fakta seputar krisis yang terjadi mulai dari awal hingga saat ini tanpa ada yang ditutupi. Kemudian status kepemilikan lahan yang menjadi sumber krisis juga sebaiknya mampu diberitakan kepada masyarakat secara jelas, baik itu lewat konferensi pers atau mengeluarkan release. Tujuannya adalah agar masyarakat tidak bingung yang mengakibatkan munculnya banyak persepsi.

\section{d. Evaluating}

Tahap ini melakukan penelitian terhadap hasil-hasil pelaksanaan program dari perencanaan, pelaksanaan program, proses komunikasi, sampai keberhasilan atau kegagalan yang terjadi dari program tersebut (dalam Nova, 2014:25). Dalam hal ini, semua tahap sudah dilakukan oleh Humasda PT. KAI Daop 2 untuk meredam krisis. Untuk kedepannya, hal yang mungkin harus lebih diperhatikan adalah Humasda Daop 2 sebaiknya mampu memberikan informasi mengenai kepemilikan lahan kepada masyarakat yang menduduki lahan tersebut dan kepada masyarakat lebih awal dengan tujuan untuk menghinadari konflik dan krisis. Selain itu, solusi yang diberikan sebaiknya adalah solusi yang dapat menolong kedua belah pihak. Selanjutnya yang mesti dperhatikan adalah komunikasi langsung kepada masyarakat untuk menunjukkan itikad baik Humasda Daop 2 dalam menyelesaikan masalah dan memberikan solusi kepada masyarakat.

\section{KESIMPULAN}

Berdasarkan hasil analisis yang didapatkan melalui wawancara terhadap 3 informan, observasi dan data dokumentasi yang peneliti dapatkan dalam melakukan penelitian ini, selanjutnya peneliti membuat simpulan yang sesuai dengan fokus permasalahan dan tujuan penelitian. Hasil simpulan yang diperoleh oleh peneliti dalam melakukan penelitian ini yaitu sebagai berikut :

\section{a. Tahapan Krisis}

Krisis yang menimpa PT. KAI Daop 2 Bandung terjadi karena Daop 2 Bandung ingin menggunakan kembali lahan yang mereka miliki sebagai lahan parkir, memperbaiki system drainase dan menata stasiun barat agar terlihat lebih bersih dan rapi. Keinginan ini kemudian diikuti dengan rencana penertiban terhadap masyarakat yang telah menetap dilahan tersebut. Rencana ini kemudian ditentang oleh masyarakat dikarenan masyarakat merasa bahwa lahan tersebut adalah milik masyarakat dan apa yang dilakukan oleh 
PT. KAI Daop 2 Bandung merupakan tindakan yang salah.

Penolakan oleh masyarakat yang berujung kepada demonstrasi dan pemberitaan di media ini kemudian dapat memberi dampak yang negatif bagi Daop 2 dalam hal citra perusahaan. Dalam menghadapi hal ini, PT. KAI memulai langkah komunikasi dengan cara melakukan sosialisasi kepada masyarakat terkait penertiban yang kemudian ditolak oleh masyarakat yang kemudian tetap melakukan aksi.

Menanggapi hal ini, Humasda Daop 2 Berkoordinasi dengan kepolisian untuk mengamankan jalannya aksi agar tidak anarkis dan merusak. Sementara untuk menjaga citra perusahaan di masyarakat, humasda Daop 2 menyiapkan strategi media relation dengan cara menyiapkan data dan fakta yang bersumber dari Humasda Daop 2 untuk kemudian disebarkan oleh media. Selain memberikan informasi secara eksternal, Humasda Daop 2 juga memberikan informasi kepada internal PT. KAI itu sendiri dengan tujuan agar PT. KAI sendiri mengetahui perkembangan kasus yang terjadi di Daop 2.

\section{b. Upaya Mengelola Krisis}

Dalam upaya mengelola krisis, langkah pertama yang dilakukan oleh PT. KAI adalah berusaha mencari informasi seputar penolakan dengan mengajak perwakilan masyarakat untuk berkomunikasi dan menanyakan alasan penolakan. Pada saat krisis terjadi, pihak Humasda Daop 2 menyiapkan data dan berkomunikasi dengan unit lain dibawah perintah Executive Vice President. Hal ini berarti langkah yang diambil oleh Humasda Daop 2 Bandung mendapat persetujuan dari semua elemen PT. KAI Daop 2 Bandung, mulai dari lapisan bawah hingga lapisan paling teratas, selain itu Humasda Daop 2 Bandung juga memperkuat relasi media.

Kemudian, Humasda Daop 2 mengambil langkah komunikasi yang lebih berfokus kepada media relation untuk menyebarkan berita seputar krisis dengan data dan fakta yang berasal dari Humasda Daop 2 Bandung. Hal ini secara konsisten dilakukan untuk membentuk citra PT. KAI yang positif di masyarakat. Pada akhirnya, seluruh pemberitaan yang muncul di media dapat menjadi sarana bagi PT. KAI untuk menjaga citra mereka di masyarakat luas.

\section{SARAN}

\section{a. Saran Praktis}

1. Berdasarkan hasil penelitian ini, peneliti merekomendasikan agar pihak Humasda Daop 2 mau melakukan komunikasi secara langsung kepada masyarakat untuk meminimalisir resiko krisis dan dampak yang ditimbulkan, berupa persepsi negatif dari masyarakat terhadap PT. KAI Daop 2 Bandung.

2. Berdasarkan hasil penelitian ini juga dapat dijadikan sebagai masukan untuk perusahaan bahwa langkah penertiban yang tidak disertai dengan komunikasi yang baik serta solusi yang bijak hanya akan menimbulkan kebencian dari masyarakat kepada perusahaan, dan membuat masyarakat terdampak penertiban merasa bahwa mereka ditindas oleh perusahaan yang mereka anggap sebagai kapitalis. 


\section{b. Saran Akademis}

Secara akademis, peneliti menyarankan kepada peneliti selanjutnya agar dapat meneliti lebih dalam lagi seputar kegiatan komunikasi yang dilakukan oleh Humasda PT. KAI Daop 2 Bandung kepada masyarakat terkait kasus penertiban lahan stasiun barat. Peneliti selanjutnya dapat menggunakan sudut pandang dari masyarakat untuk menggali lebih dalam seputar kegiatan komunikasi yang dilakukan oleh Humasda PT. KAI Daop 2 Bandung, serta menyertakan satu pihak netral yang berasal dari ahli atau pengamat komunikasi. Sehingga nantinya hasil penelitian akan lebih beragam karena berasal dari sudut pandang yang berbeda.

\section{DAFTAR RUJUKAN}

Darmastuti, Rini. (2012). Media Relations, Konsep, Strategi dan Aplikasi. Yogyakarta: Andi Offset.

Gassing, Syarifuddin S, Suryanto. (2016). Public relationss. Yogyakarta: Andi Offset.

Iriantara, Yosal. (2011). Media Relations, Konsep, Pendekatan dan Praktik (Cetakan ke-3). Bandung: Simbiosa Rekatama Media.

Kriyantono, Rachmat. (2015). Public relationss, Issue \& Crisis Mangement. Jakarta: Prenada Media Group.

Nova, Firsan. (2014). PR WAR. Jakarta: Gramedia Widiasarana Indonesia.

Ruslan, Rosady. (1999). Manajemen Humas dan Manajemen Komunikasi (Persepsi dan Aplikasi) (Cetakan ke2). Jakarta: RajaGrafindo Persada. 